\title{
The Small GTPase RhoA Is Required to Maintain Spinal Cord Neuroepithelium Organization and the Neural Stem Cell Pool
}

\author{
Dominik Herzog, ${ }^{1,5}$ Pirmin Loetscher, ${ }^{1}$ Jolanda van Hengel, ${ }^{2,3}$ Sebastian Knüsel, ${ }^{1}$ Cord Brakebusch, ${ }^{4}$ Verdon Taylor, ${ }^{5,6}$ \\ Ueli Suter, ${ }^{1}$ and João B. Relvas ${ }^{1,7}$ \\ ${ }^{1}$ Institute of Cell Biology, Department of Biology, Eidgenössische Technische Hochschule Zürich, CH-8093 Zürich, Switzerland, ${ }^{2}$ Molecular Cell Biology \\ Unit, Department for Molecular Biomedical Research, Vlaams Instituut voor Biotechnologie, B-9052 Ghent, Belgium, ${ }^{3}$ Department of Biomedical Molecular \\ Biology, Ghent University, B-9000 Ghent, Belgium, ${ }^{4}$ Biomedical Institute, Biotech Research and Innovation Center, University of Copenhagen, 2200 \\ Copenhagen, ${ }^{5}$ Department of Molecular Embryology, Max Planck Institute of Immunobiology, D-79011 Freiburg, Germany, ${ }^{6}$ Centre for Stem Cell Biology, \\ Department of Biomedical Science, University of Sheffield, Western Bank, Sheffield, S10 2TN, United Kingdom, and 'Instituto de Biologia Molecular e \\ Celular, Universidade do Porto, 4150-180 Porto, Portugal
}

The regulation of adherens junctions (AJs) is critical for multiple events during CNS development, including the formation and maintenance of the neuroepithelium. We have addressed the role of the small GTPase RhoA in the developing mouse nervous system using tissue-specific conditional gene ablation. We show that, in the spinal cord neuroepithelium, RhoA is essential to localize N-cadherin and $\beta$-catenin to AJs and maintain apical- basal polarity of neural progenitor cells. Ablation of RhoA caused the loss of AJs and severe abnormalities in the organization of cells within the neuroepithelium, including decreased neuroepithelial cell proliferation and premature cell-cycle exit, reduction of the neural stem cell pool size, and the infiltration of neuroepithelial cells into the lumen of the ventricle. We also show that, in the absence of RhoA, its effector, mammalian diaphanous-related formin 1 (mDial), does not localize to apical AJs in which it likely stabilizes intracellular adhesion by promoting local actin polymerization and microtubule organization. Furthermore, expressing a dominant-negative form of mDial in neural stem/progenitor cells results in a similar phenotype compared with that of the RhoA conditional knock-out, namely the loss of AJs and apical polarity. Together, our data show that RhoA signaling is necessary for AJ regulation and for the maintenance of mammalian neuroepithelium organization preventing precocious cell-cycle exit and differentiation.

\section{Introduction}

Neurons and glial cells of the CNS arise from a homogeneous pool of proliferating, undifferentiated neuroepithelial cells (NEPs), known as the neuroepithelium. There, bipolar NEPs extend processes that contact both the luminal (apical) and pial (basal) surfaces of the neural tube and form the ventricular zone (VZ). In the VZ, the NEPs contain adherens junctions (AJs) at the

\footnotetext{
Received Sept. 13, 2010; revised Jan. 31, 2011; accepted Feb. 4, 2011.

D.H., V.T., and J.B.R. designed research; D.H., P.L., and S.K. performed research; J.v.H. and C.B. contributed unpublished reagents/analytic tools; D.H., U.S., and J.B.R. analyzed data; D.H., V.T., U.S., and J.B.R. wrote the paper.

This work was supported by the Swiss National Science Foundation and by the National Center of Competence in Research "Neural Plasticity and Repair." Research in the Taylor laboratory was supported by the Deutsche Forschungsgemeinschaft (TA-310-2 to V.T.), Landesstiftung Baden-Württemberg (ASII/29 to V.T.), and the Max Planck Society. Research in the Relvas laboratory was supported by Fundação para a Ciência e Tecnologia of Portugal Grant PTDC/BIA-BCM/112730/2009. We thank L. Sommer and N. Mantei for valuable advice and discussions and E. B. Crenshaw and P. Soriano for providing transgenic animals. We also thank the Light Microscopy Centre of the Eidgenössische Technische Hochschule Zürich for technical help with confocal imaging. The Islet-1 monoclonal antibody developed by T. M. Jessel was obtained from the Developmental Studies Hybridoma Bank developed under the auspices of the National Institute of Child Health and Human Development and maintained by The University of lowa, Department of Biology (lowa City, IA). The Par3 antibody was a kind gift from I. Macara (Charlottesville, VA). The DN mDia1 expression plasmid mDia1 F2 $\Delta$ N1 YFP was a kind gift from Dr. A. Alberts (Van Andel Institute, Grand Rapids, MI). The GST PAK/crib domain construct was provided by J. Collard (The Netherlands Cancer Institute, Amsterdam, The Netherlands).

The authors declare no competing financial interests.

Correspondence should be addressed to João B. Relvas, Instituto de Biologia Molecular e Celular, Universidade do Porto, Rua do Campo Alegre 823, 4150-180 Porto, Portugal. E-mail: jrelvas@ibmc.up.pt.

DOI:10.1523/JNEUROSCI.4807-10.2011

Copyright $\odot 2011$ the authors $\quad 0270-6474 / 11 / 315120-11 \$ 15.00 / 0$
}

luminal boundary (Aaku-Saraste et al., 1996) whose functions are critical to maintain cell-cell adhesion and the integrity of the VZ. NEPs can undergo two different kinds of division: symmetric, resulting in two identical daughter cells that inherit equal microdomains within their AJ structure and remain at the VZ; and asymmetric (or neurogenic) in which one daughter cell remains in the VZ and the other that ultimately loses its adhesive proteins and will migrate toward the basal side of the neuroepithelium and differentiates (Götz and Huttner, 2005; Kriegstein and AlvarezBuylla, 2009). It has been suggested that the unequal distribution of functionally distinct AJ microdomains during NEP asymmetric division influences the partitioning of fate determinants, a decisive step in neurogenesis (Kosodo et al., 2004; Marthiens and ffrench-Constant, 2009). Gene-ablation studies in mice revealed that N-cadherin and its cytoplasmic partners, $\alpha^{-}, \beta$-, and p120catenin, play an important role in AJ formation (Lien et al., 2006a). AJs comprise a cadherin-catenin complex in which the extracellular domains of the cadherins of neighboring cells interact in a $\mathrm{Ca}^{2+}$ dependent homophilic manner, thereby promoting cell-cell adhesion, and the intracellular domain connects via the catenins to the actin cytoskeleton (Gumbiner, 2005). Cadherin-mediated cell-cell adhesion is regulated by different developmental and cellular signals (Gumbiner, 2005), including those generated by the Rho family of small GTPases (Samarin and Nusrat, 2009).

Rho GTPases not only regulate signaling pathways linking extracellular stimuli to the assembly and organization of the 
actin cytoskeleton (Hall, 1998) but also control cellular functions, such as cell-cycle progression, survival and differentiation, cell polarization, and cell adhesion among many others (Jaffe and Hall, 2005). Rho GTPases have distinct, although partially overlapping, sets of effectors, and thus it is likely that they have specific functions in neural stem and progenitor cells. In CNS development, the roles of Cdc42 (Cappello et al., 2006; Chen et al., 2007) and Rac1 (Chen et al., 2006, 2009; Leone et al., 2010) have been elucidated in forebrain and oligodendrocyte development (Thurnherr et al., 2006). Here, using tissue-specific conditional ablation of RhoA in NEPs, we report for the first time key roles for RhoA in mammalian CNS development. We show that NEPs in the spinal cord VZ require RhoA to maintain AJ integrity at their apical membranes. Expression of a dominant-negative (DN) form of mammalian diaphanous-related formin 1 (mDial) in neural stem/progenitor cells in vivo also leads to a similar loss of AJs and apical polarity, suggesting that RhoA may act in an mDial-dependent manner. Ablation of RhoA leads to severe defects in the organization of the $\mathrm{VZ}$ and consequently to precocious differentiation and a concomitant reduction in the neural stem cell pool.

\section{Materials and Methods}

Generation of conditional knock-out mice. Mice homozygous for the floxed RhoA allele ( $\mathrm{RhoA}^{\text {lox/lox }}$, which will be described in detail elsewhere, were crossed with mice heterozygous for RhoA floxed allele and additionally expressing the Cre recombinase under control of the Brn4 promoter (Zechner et al., 2003) (Brn4-Cre ${ }^{+}$Rho $^{\text {lox/wt }}$ ) to obtain Brn4$\mathrm{Cre}^{+} \mathrm{Rho}^{\text {lox/lox }}$ mice (hereafter called RhoA mutant mice) and Brn4$\mathrm{Cre}^{+} \mathrm{Rho}^{\text {lox/wt }}$ mice that showed no overt phenotype (hereafter called control mice). The conditional lac $Z$ gene from the ROSA26 reporter mouse strain (Soriano, 1999) was also bred into the mouse lines described above allowing the detection of Cre-recombined cells. Genotyping was done by PCR on genomic DNA. All animal experiments were approved by the veterinary office of the Canton of Zurich, Switzerland and Max Planck institutional and German Federal regulations and under license numbers H-05/01, 0-06/02, G-09/18, and G-09/19.

Immunohistochemistry and terminal deoxynucleotidyl transferasemediated biotinylated UTP nick end labeling staining. Embryos of either sex were obtained from timed-mated animals. The date of plug was defined as embryonic day 0.5 (E0.5). They were fixed in $4 \%$ paraformaldehyde (PFA). When required, $10 \mu \mathrm{l} / \mathrm{g}$ bromodeoxyuridine (BrdU) $(10$ $\mathrm{mm}$; Roche) was injected intraperitoneally into pregnant mothers $20 \mathrm{~h}$ before they were killed. For paraffin sections, embryos were dehydrated in a serial series of ethanol, paraffinized, and microtome sectioned in $5 \mu \mathrm{m}$ sections. For frozen sections, embryos were cryopreserved overnight in 30\% sucrose, frozen in O.C.T (Sakura), and cryosectioned in $20 \mu \mathrm{m}$ sections.

Hematoxylin-eosin (H\&E) staining was done according to standard protocols.

Terminal deoxynucleotidyl transferase-mediated biotinylated UTP nick end labeling staining. Deparaffinized sections were washed in PBS for 10 min and blocked for $1 \mathrm{~h}$ with $10 \%$ goat serum, $1 \%$ Triton X-100, and $0.1 \%$ BSA in PBS. Terminal deoxynucleotidyl transferase-mediated biotinylated UTP nick end labeling (TUNEL) assays were performed according to the instructions of the manufacturer (Roche).

Immunohistochemistry (paraffin sections). Deparaffinized sections were subjected to antigen retrieval in a tissue processor for $20 \mathrm{~min}$ at $98^{\circ} \mathrm{C}$ in $40 \mathrm{~mm}$ Tris- $\mathrm{HCl}$ and $2 \mathrm{~mm}$ EDTA, pH 9. Sections were blocked for $1 \mathrm{~h}$ in $1 \%$ BSA in PBS and incubated with primary antibody solution $(0.05 \%$ BSA in PBS) overnight at $4^{\circ} \mathrm{C}$. Sections were washed in PBS, incubated for $1 \mathrm{~h}$ in secondary antibody solution at room temperature (RT), washed in PBS, counterstained with 4',6-diamidino-2-phenylindole (DAPI), and mounted in Immu-Mount (Thermo Fisher Scientific). For exposing the BrdU antigen, sections were additionally incubated in $2 \mathrm{M}$ $\mathrm{HCl}$ for $20 \mathrm{~min}$ at RT after antigen retrieval.
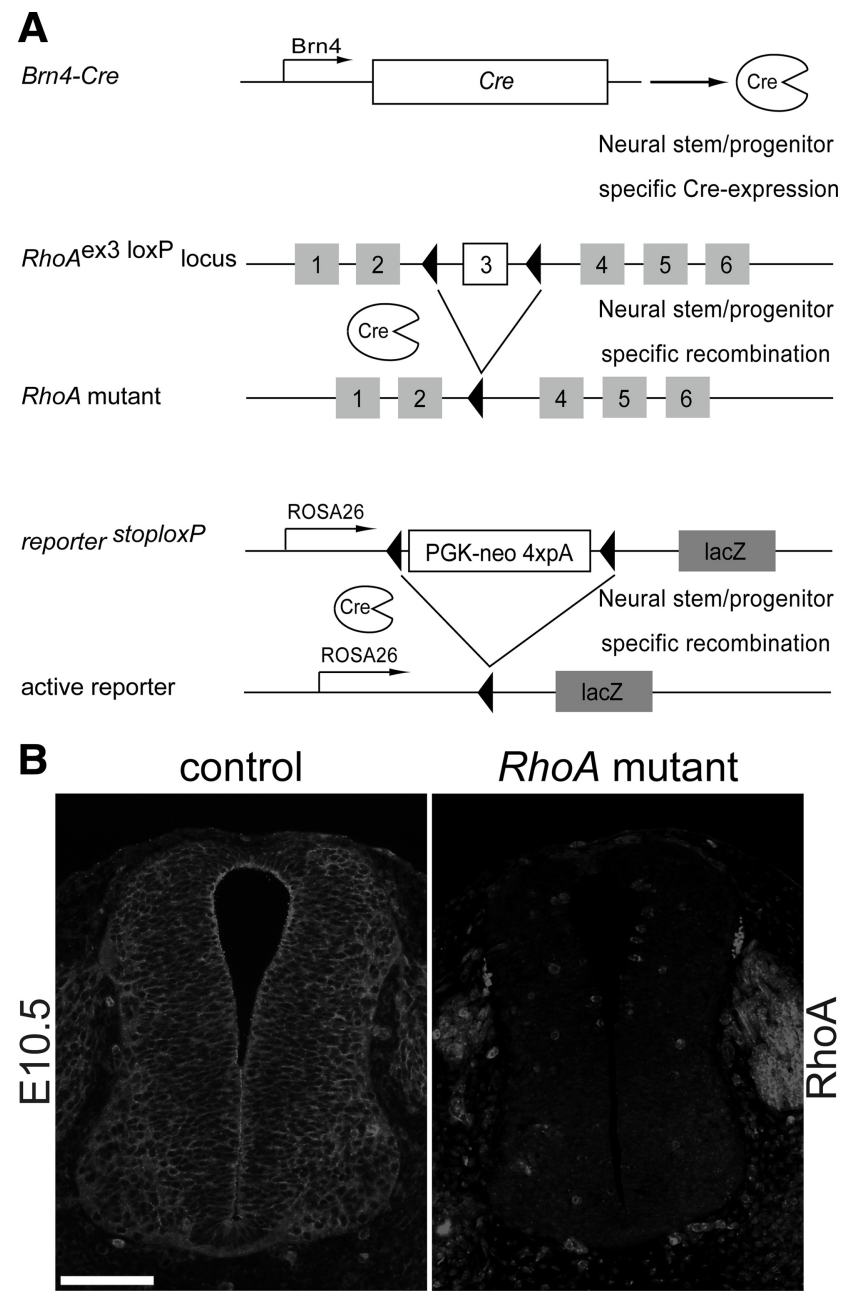

Figure 1. Recombination of the conditional RhoA allele in NEPs of the spinal cord. $\boldsymbol{A}$, Regulatory sequences of the Brn4 promoter drive the expression of the Cre recombinase in NEPs. During Brn4-Cre-mediated recombination the genomic region between the LoXP sites is excised; in case of the conditional RhoA allele, exon 3 is excised leading to the inactivation of the RhoA gene. Recombination of the lac $Z$ reporter gene leads to the expression of $\beta$-galactosidase in recombined neuroepithelial cells. $\boldsymbol{B}$, Immunohistochemistry on forelimb spinal cord crosssections of E10.5 embryos demonstrates efficient loss of RhoA protein in the spinal cord but not in other tissues. Scale bar, $100 \mu \mathrm{m}$.

Immunohistochemistry (frozen sections). Sections were air dried, washed in PBS, blocked for $1 \mathrm{~h}$ in 2\% BSA and $0.2 \%$ Triton X-100 in PBS, incubated overnight at $4^{\circ} \mathrm{C}$ with primary antibody diluted in $0.05 \%$ BSA in PBS, washed in PBS, incubated for $1 \mathrm{~h}$ in secondary antibody solution, washed in PBS, and mounted in Immu-Mount. Immunohistochemistry for $\mathrm{mDia}$ and for the in utero electroporation experiments was performed on frozen sections.

For all immunostainings, a minimum of two sections in the case of TUNEL staining and a minimum of three sections in all other cases, obtained from at least three embryos per stage and per genotype from different litters were analyzed. All images were acquired using Carl Zeiss fluorescence microscopes (Axioplan 2; with objectives $20 \times / 0.5,40 \times 1$ 0.75 , and $100 \times / 1.3$ ) equipped with Carl Zeiss AxioCam CCD cameras (AxioCam HR or AxioCamMRm). The acquisition software was AxioVision 4.6 (Carl Zeiss). The images were further processed (levels adjusted) using Photoshop CS3 (Adobe Systems).

The following antibodies were used for this study: monoclonal antibodies against $\beta$-actin (Sigma-Aldrich), BrdU (BD Biosciences), Islet-1 (Developmental Studies Hybridoma Bank), Ki67 (Dako), mDial (BD Biosciences), N-cadherin (BD Biosciences), Nestin (BD Biosciences), neuronal-specific nuclear protein (NeuN) (Millipore), RhoA (Santa 
Cruz Biotechnology), ROCK1 (BD Bioscience); polyclonal antibodies against $\beta$-Catenin (Sigma-Aldrich), Doublecortin (Santa Cruz Biotechnology), Laminin (Sigma-Aldrich), neurofilament (Millipore), Olig2 (Millipore), Par3 (Ian Macara, University of Virginia, Charlottesville, VA), PKCל (Santa Cruz Biotechnology), and Sox2 (Santa Cruz Biotechnology). Secondary antibodies coupled with Alexa Fluor-488 (Invitrogen) or coupled with cyanine 3 (Jackson ImmunoResearch) were used.

In situ hybridization. Nonradioactive in situ hybridization with digoxigenin-labeled riboprobes was performed on cryosections $(20 \mu \mathrm{m})$ as described previously (Paratore et al., 1999). Nitroblue-tetrazolium-chloride/5-bromo-4-chlorindolyl-phosphate (Roche Diagnostics) were used as chromogens to visualize hybridization signals. Antisense riboprobes were labeled with digoxigenin according to the instructions of the manufacturer (Roche Diagnostics).

Neurosphere cell culture. Fibroblast growth factor (FGF)/epidermal growth factor (EGF)dependent neurosphere cell cultures were generated from E13.5 mouse embryos. The neural tube was dissociated for $20 \mathrm{~min}$ in $200 \mu \mathrm{l}$ of PPD solution $(2.5 \mathrm{U} / \mathrm{ml}$ papain, $100 \mathrm{U} / \mathrm{ml}$ DNase 1 , and $1 \mathrm{U} / \mathrm{ml}$ dispase) at $37^{\circ} \mathrm{C}$, and reaction was stopped by adding $1 \mathrm{ml}$ of ovomucoid mix ( $1 \mathrm{mg} / \mathrm{ml}$ trypsin inhibitor, $0.5 \mathrm{mg} / \mathrm{ml}$ $\mathrm{BSA}$, and $80 \mathrm{U} / \mathrm{ml}$ DNase 1). Cells were mechanically triturated and cultured in suspension in neurosphere medium (DMEM/F-12 supplemented with B27, $20 \mathrm{ng} / \mathrm{ml}$ basic FGF, and $10 \mathrm{ng} / \mathrm{ml} \mathrm{EGF).} \mathrm{Cells} \mathrm{obtained} \mathrm{from} \mathrm{one} \mathrm{embryo}$ were grown in a well of a six-well plate at $37^{\circ} \mathrm{C}$, $5 \% \mathrm{CO}_{2}$ in $4 \mathrm{ml}$ of medium, and another $4 \mathrm{ml}$ of medium was added 3-4 d after isolation. After $7 \mathrm{~d}$ in culture, neurospheres were passaged.

For analyzing stem cell self-renewal, 1000 cells were seeded per well in a 24 -well plate in $0.5 \mathrm{ml}$ of conditioned medium. After 3-4 d in culture, $0.5 \mathrm{ml}$ of conditioned medium was added. After $7 \mathrm{~d}$ in culture, spheres were fixed by adding PFA to a final concentration of $2 \%$, washed in PBS, and stained with 5-bromo-4chloro-3-indolyl- $\beta$-D-galactopyranoside (X-Gal). The number of grown neurospheres was quantified using a stereomicroscope. Additionally, spheres were further passaged from these lowdensity cultures. At least four embryos per genotype obtained from two different litters were taken into culture and analyzed.

Immunofluorescence and X-Gal staining on neurosphere cell cultures. Neurosphere cell cultures were fixed for $5 \mathrm{~min}$ in 2\% PFA and washed in PBS, and X-Gal staining was done according to standard protocols.

For immunofluorescence, neurospheres were blocked for $1 \mathrm{~h}$ in $1 \%$ BSA in PBS after fixation and incubated with primary antibody solution $\left(0.05 \%\right.$ BSA in PBS) overnight at $4^{\circ} \mathrm{C}$. Spheres were washed in PBS, incubated for $1 \mathrm{~h}$ in secondary antibody solution at RT, washed in PBS and counterstained with DAPI, and mounted in Immu-Mount (Thermo Fisher Scientific). Confocal images were acquired using a Leica SP1-2 laser scanning microscope (with $63 \times$ $0.6-1.32$ objective). The acquisition software was LCS (Leica), and $z$-projections were processed in NIH ImageJ.

$\mathbf{E}$

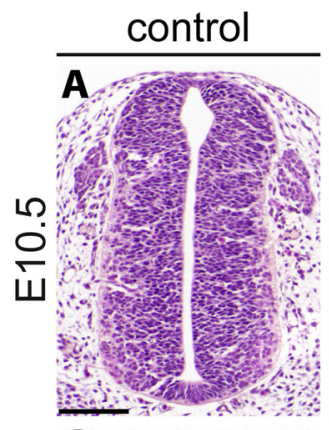

RhoA mutant

control

RhoA mutant

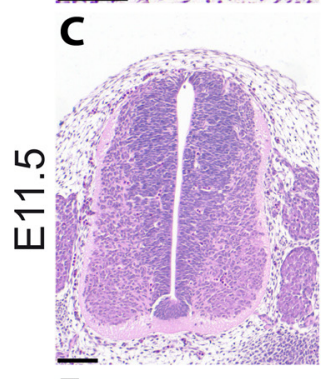

B

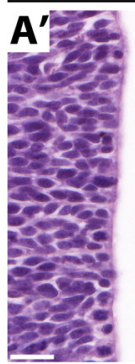

D
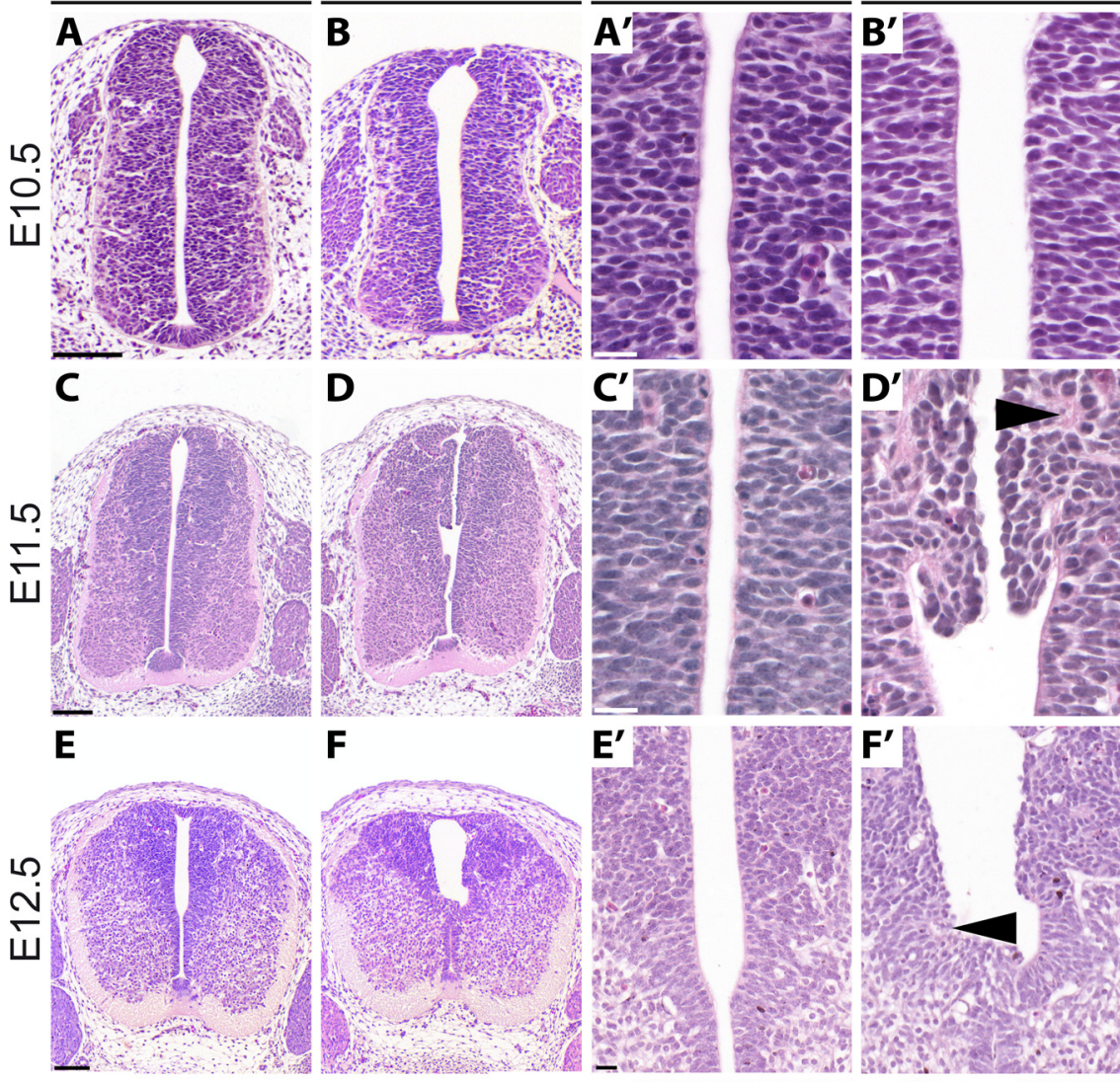

$\mathbf{F}$

$\mathbf{C}^{\prime}$
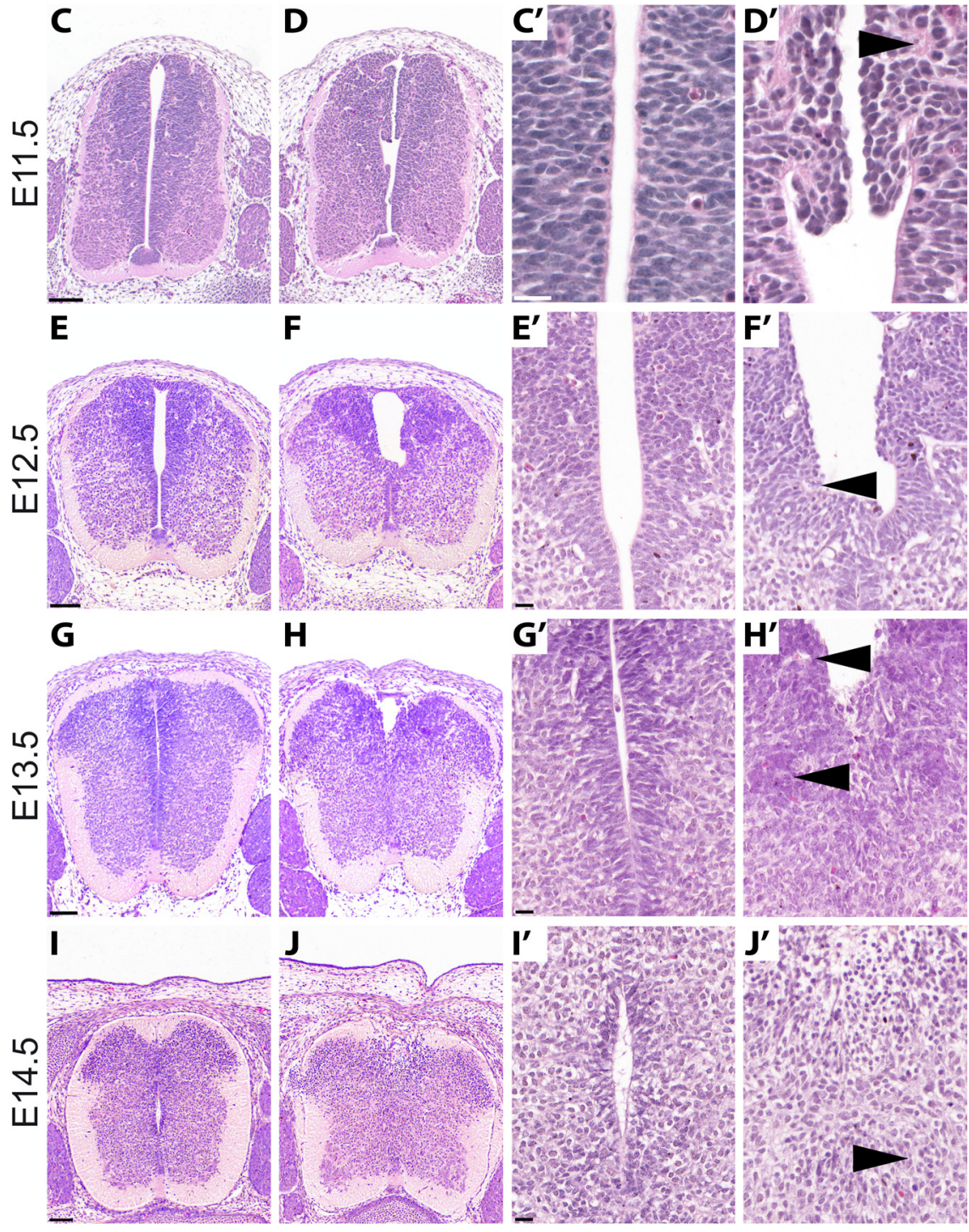

Figure 2. RhoA is required for the organization of the ventricular zone. $A-J$, Spinal cord cross-sections stained with hematoxylin and eosin; magnifications of the lumen and the central spinal cord region $\left(\boldsymbol{A}^{\prime}-J^{\prime}\right)$. Early in development $(\boldsymbol{A}, \boldsymbol{B})$, the ventricular structure is normal in mutant spinal cords and the lumen is formed correctly. At E11.5, mutant spinal cords show dysplasias. Compared with controls $\left(\boldsymbol{C}, \boldsymbol{C}^{\prime}\right)$, the normal epithelial organization is lost and the ventricular structure is disorganized with formation of rosette-like structures and invasive mesenchymal-like cells present in the spinal cord lumen $\left(\boldsymbol{D}, \boldsymbol{D}^{\prime}\right)$. At E12.5, the epithelial organization of the $\mathrm{VZ}$ is progressively lost in mutant spinal cords $\left(\boldsymbol{F}, \boldsymbol{F}^{\prime}\right)$ compared with controls $\left(\boldsymbol{E}, \boldsymbol{E}^{\prime}\right)$. At E13.5, cells from the VZ dispersed throughout the mutant spinal cords and the lumen almost disappeared $\left(\boldsymbol{H}, \boldsymbol{H}^{\prime}\right.$ compared with $\left.\mathbf{G}_{\mathbf{G}} \boldsymbol{G}^{\prime}\right)$. Subsequently, at E14.5, the VZ and the lumen of RhoA mutant spinal cords completely disappeared $\left(J, J^{\prime}\right.$ compared with $\left.I^{\prime}, I^{\prime}\right)$. Arrowheads point to rosette-like structures present in mutant spinal cords. Scale bars: $A-J, 100 \mu \mathrm{m} ; \boldsymbol{A}^{\prime}-J^{\prime}, 20 \mu \mathrm{m}$.

Rho GTPase activity assay on neurosphere cell culture lysates. A glutathione $S$-transferase-p21-activated kinase-crib domain construct was provided by J. Collard (The Netherlands Cancer Institute, Amsterdam, The Netherlands). Cdc42 and Rac1 activity were measured as described pre- 
A control RhoA mutant B

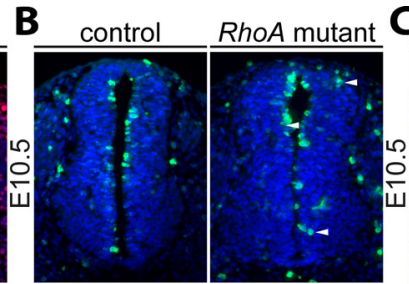

\section{C control}

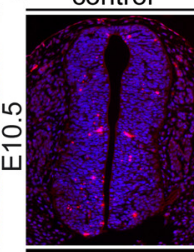

RhoA mutant
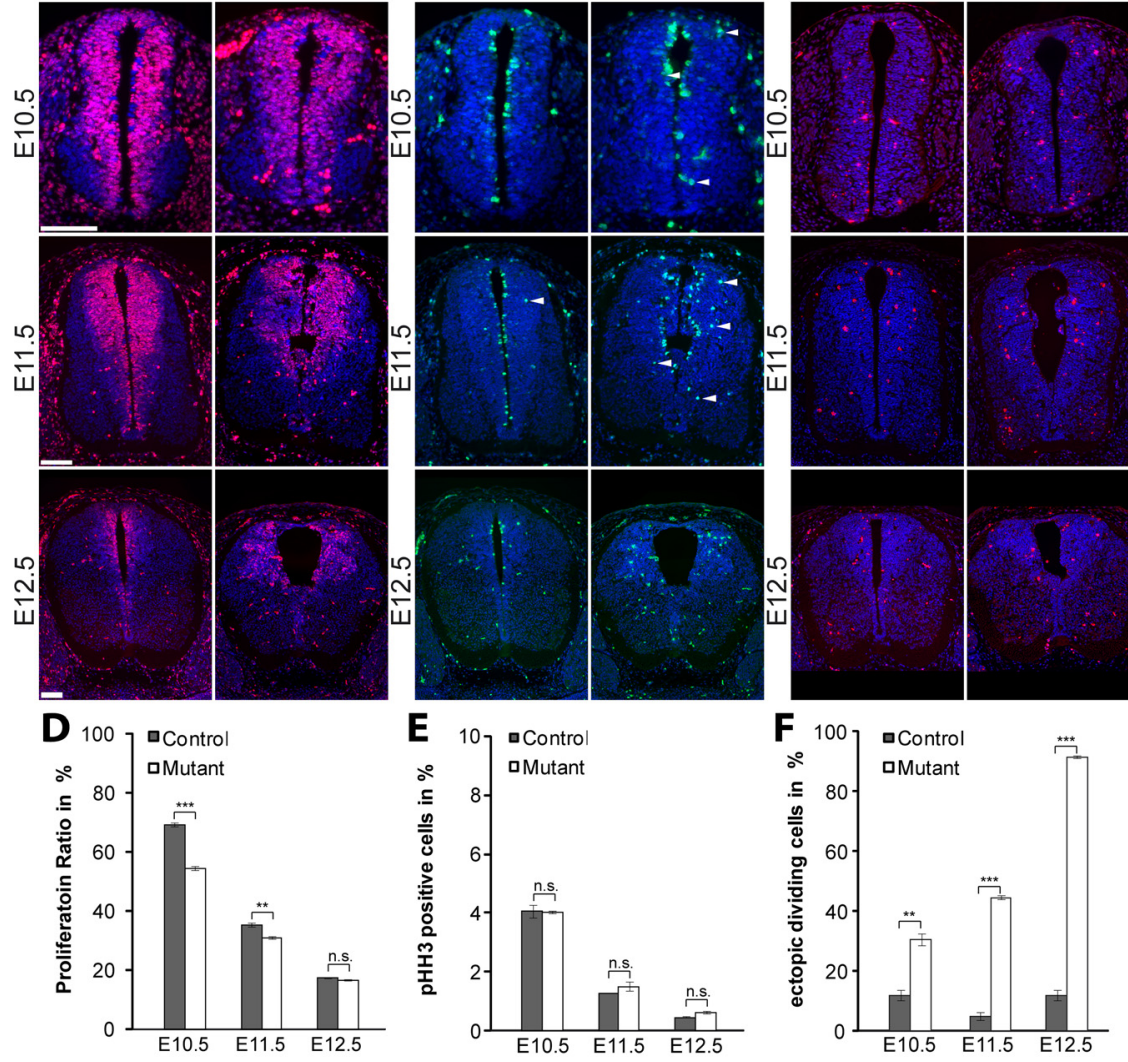

G
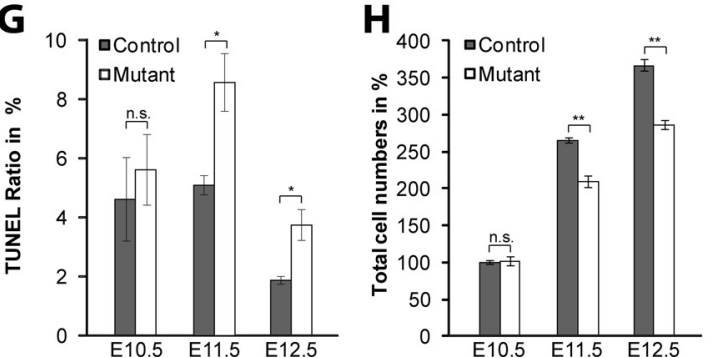

Figure 3. RhoA is required for proliferation, survival, and localization of mitotic cells. $\boldsymbol{A}-\boldsymbol{C}$, Proliferation was assessed in control and mutant spinal cords by expression of Ki67 $(\boldsymbol{A})$ and mitotic marker phospho-histone-H3 $(\boldsymbol{B})$. Cell death was examined by TUNEL in control and mutant spinal cords $(\boldsymbol{C})$. $\boldsymbol{D}$, The proliferation ratio was determined by the quotient of Ki67-positive cells per total cells of the spinal cord. At E10.5, before apparent morphological defects, the proliferation ratio was significantly decreased from $69.29 \pm 0.66 \%$ in the control to $54.28 \pm 0.62 \%$ in the mutant $(n=3, p=0.0001)$ and at E11.5 from $35.35 \pm 0.7 \%$ in the control to $30.96 \pm 0.49 \%$ in the mutant $(n=3, p=0.0069)$, respectively. At E12.5, the proliferation ratio in the control $(17.39 \pm 0.23 \%)$ was not significantly altered compared with the mutant (16.57 \pm $0.13 \%)$. $E$, The relative number of mitotic cells in the spinal cord was examined by quantification of phosphor-histone-H3positive cells to total spinal cord cells. The percentage of mitotic cells was unchanged between control (E10.5, $4.04 \pm$ $0.2 \%$; E11.5, $1.27 \pm 0.01 \% ; E 12.5,0.44 \pm 0.03 \%$ ) and mutant (E10.5, $4 \pm 0.05 \% ; E 11.5,1.48 \pm 0.15 \% ; E 12.5,0.61 \pm$ $0.03 \%$ ) spinal cords. $\boldsymbol{F}$, Whereas the relative number of mitotic cells was unchanged, more cells that are not dividing at the ventricular surface can be observed in the mutant spinal cords (arrows in $\boldsymbol{B}$ ). The ratio of non-ventricular dividing cells to all mitotic cells was quantified and is significantly increased in the mutant $(E 10.5,30.56 \pm 2.05 \%$; $E 11.5,44.16 \pm 0.58 \%$; $E 12.5,91.35 \pm 0.46 \%)$ compared with control (E10.5, $11.67 \pm 1.81 \%$; E11.5, $4.68 \pm 1.17 \%$; E12.5, $11.63 \pm 1.74 \%)$ spinal cords at all stages analyzed (E10.5, $n=3, p=0.0014 ; \mathrm{E} 11.5, n=3, p=0.0001 ; \mathrm{E} 12.5, n=3, p=0.0001)$. G, The ratio of TUNEL-positive cells to total cells present in control and mutant spinal cords was quantified. At E10.5, no significant difference can be observed between control ( $4.6 \pm 1.43 \%$ ) and mutant (5.6 $\pm 1.21 \%)$. At E11.5, a significant increase in the ratio of TUNEL-positive cells from $5.07 \pm 0.33 \%$ in the control to $8.56 \pm 0.97 \%$ in the mutant was found $(n=3, p=$ 0.0273 ) and at E12.5 from $1.86 \pm 0.13 \%$ in the control to $3.75 \pm 0.53 \%$ in the mutant $(n=3, p=0.0259)$. $\boldsymbol{H}$, The decreased proliferation and increased cell death leads to a significant lower number of cells present in mutant spinal cords from E11.5 onward. The total cell number was determined by quantifying DAPI-positive nuclei, and the numbers of cells at E10.5 in the control spinal cord were set to 100\% (control: E10.5, $100 \pm 2.59 \%$; E11.5, 264.37 \pm 3.4\%; E12.5, $365.77 \pm$ 7.35\%; mutant: E10.5, 101.02 \pm 6.51\%; E11.5, $208.80 \pm 7.52 \%$; E12.5, 285.64 $\pm 6.01 \%)$. Scale bars, $100 \mu \mathrm{m}$. viously (Sander et al., 1998; Benninger et al., 2007). In brief, neurospheres from bulk cell culture were collected by centrifugation, lysed in FISH buffer [ $10 \%$ glycerol, $50 \mathrm{~mm}$ Tris- $\mathrm{HCl}$, $\mathrm{pH} 7.4,100 \mathrm{~mm} \mathrm{NaCl}, 1 \% \mathrm{NP}-40,2 \mathrm{~mm} \mathrm{MgCl}_{2}$, and protease inhibitor cocktail (SigmaAldrich)], and centrifuged for $5 \mathrm{~min}$ at $21,000 \times g$ at $4^{\circ} \mathrm{C}$. Aliquots of exactly $10 \%$ of the volume were taken from the supernatant to determine the total protein amounts. The remaining supernatant was incubated with the bait proteins bound to glutathione-coupled Sepharose beads (GE Healthcare) at $4^{\circ} \mathrm{C}$ for 30 $\mathrm{min}$. The beads and proteins bound to the fusion protein were washed three times in an excess of FISH buffer, eluted in Laemli's sample buffer, and analyzed for bound Cdc42 and Racl molecules by standard Western blotting. The following antibodies were used: monoclonal antibodies against Racl (Millipore) and glyceraldehyde-3-phosphate dehydrogenase (HyTest), and polyclonal antibody against Cdc42 (Abcam). Secondary antibodies were obtained from Promega and Southern Biotechnology. Bands were quantified using Quantity One software (Bio-Rad). Lysates were generated from three independent cultures per genotype.

In utero electroporation. The DN mDial ( $m$ Dial F2 $\Delta \mathrm{N} 1$ ) was cloned into the pCAGGS mammalian expression vector (Niwa et al., 1991) according to standard techniques. The construct was shown to be functional in $3 \mathrm{~T} 3$ fibroblast transfections (supplemental Fig. 7A, available at www.jneurosci.org as supplemental material). Green fluorescent protein (GFP) was cloned into the pCAGGS expression vector and used in control and in cotransfection experiments. In utero electroporation was performed at E12.5 as described previously (De Pietri Tonelli et al., 2006). Briefly, C57BL/6J mice (defined as $0.5 \mathrm{~d}$ of gestation in the morning of vaginal plug) were anesthetized with isoflurane (Baxter), and their uteri were exposed. Endotoxin-free plasmid stocks were resuspended in sterile PBS at $1-3 \mu \mathrm{g} / \mu \mathrm{l}$, and fast green contrast dye added to the DNA (10\% final concentration) to better visualize the injection site. By using a glass capillary, $1-2 \mu \mathrm{l}$ of DNA were injected into the ventricle of the embryonic telencephalon, and six pulses with a pulse length of $50 \mathrm{~ms}$ and in an interval of 950 $\mathrm{ms}$ of $40 \mathrm{~V}$ were delivered through platinum electrodes (1 mm diameter) and an electroporator (Electro Square Pavator; BTX Harvard Apparatus). The uterus was then relocated into the peritoneal cavity, and the abdomen was sutured. Embryos were isolated $24 \mathrm{~h}$ after transfection. Embryos were isolated and fixed in $4 \%$ paraformaldehyde at $4^{\circ} \mathrm{C}$ overnight, cryoprotected in a $30 \%$ sucrose solution, embedded in tissue O.C.T. (TissueTek), and stored at $-80^{\circ} \mathrm{C}$. Pictures were obtained using a Carl Zeiss LSM510 confocal microscope, and $z$-projections were processed using the Carl Zeiss LSM imaging software.

Statistical analysis. The data show the mean \pm SEM. Statistical significance was determined using a two-tailed Student's $t$ test. 
Significance was set at ${ }^{*} p<0.05,{ }^{* *} p<0.01$, and ${ }^{* *} p<0.001 . n$ indicates the number of independent experiments performed.

\section{Results}

\section{Conditional ablation of RhoA in the spinal cord}

We conditionally ablated RhoA by expressing Cre recombinase under the control of the Brn 4 regulatory sequences (Fig. $1 A$ ). In this experimental setting, Cre is already expressed and active in NEPs of the developing spinal cord at E10 (Zechner et al., 2003). We included the conditional ROSA26 reporter allele (Soriano, 1999) into the breeding strategy to be able to identify and lineage trace recombined cells in both control and mutant mice (Fig. $1 A)$. Recombination of the conditional RhoA alleles led to the loss of RhoA in the spinal cord of mutant mice from E10.5 (Fig. $1 B$ ). RhoA-deficient mice died at late embryonic stages, and we never observed live-born mutants.

\section{RhoA is required for the integrity of the ventricular region}

The loss of RhoA caused severe defects in the organization of the developing spinal cord (Fig. 2). H\&E staining of transverse sections of embryos between E10.5 and E14.5 at the level of the developing spinal cord revealed that RhoA mutants had severe morphological defects from E11.5 onward. In contrast to the spinal cords of control embryos (Fig. $2 A, C, E, G, I, A^{\prime}, C^{\prime}, E^{\prime}, G^{\prime}, I^{\prime}$ ), mutant spinal cords lacked a well-organized VZ (Fig. $2 B, D, F$, $\left.H, J, B^{\prime}, D^{\prime}, F^{\prime}, H^{\prime}, J^{\prime}\right)$ and showed dysplasias, probably resulting from neuroepithelial cells that had invaded the lumen of the neural tube (Fig. $2 D, D^{\prime}$ ). Rosette-like structures, similar to those found in primitive neuroepithelial tumors, were present in the $\mathrm{VZ}$ of mutant spinal cords indicative of alterations in NEP adhesion (Fig. $2 D^{\prime}, F^{\prime}, H^{\prime}, J^{\prime}$, arrowheads). At E14.5, the VZ and the neural tube lumen were completely missing (Fig. $2 J, J^{\prime}$ ).

\section{RhoA is required for cell proliferation and survival in the ventricular region}

Next, we analyzed the percentage of proliferating, Ki67-positive cells in the spinal cord between E10.5 and E12.5 (Fig. 3A). The percentage of $\mathrm{VZ}$ cells that were mitotically active and expressed Ki67 was significantly reduced in both E10.5 and E11.5 mutant spinal cords compared with controls (Fig. 3D). This likely contributed to the significantly reduced total number of cells present in the mutant spinal cords at E11.5 and E12.5 (Fig. 3H). Although the proportion of mitotic VZ cells in the spinal cord, marked by phospho-histone-H3, was not significantly different in the mutants compared with controls (Fig. $3 B, E$ ), the percentage of mitotic cells dividing at locations away from the luminal surface was significantly higher in mutants compared with controls (Fig. $3 B, F$ ).

We also quantified the numbers of apoptotic, TUNELpositive cells in mutant and control spinal cords (Fig. 3C,G). Our data show that, at E11.5 and E12.5, there was a significant increase in the percentage of cells undergoing apoptosis in mutants compared with controls (Fig. 3G). We conclude that lower proliferation and increased cell death likely contribute to the reduction in total cell numbers observed in the spinal cords of RhoA mutant embryos (Fig. $3 H$ ).

\section{Loss of RhoA leads to early cell-cycle exit and precocious neuronal differentiation}

The reduction in the proportion of cells in the mutant spinal cord that proliferate at E10.5 and E11.5 could be caused by their premature exit from the cell cycle. To investigate this, we performed $\mathrm{S}$-phase labeling of cells by injecting BrdU into time-mated females and analyzing the spinal cords of control and mutant em-
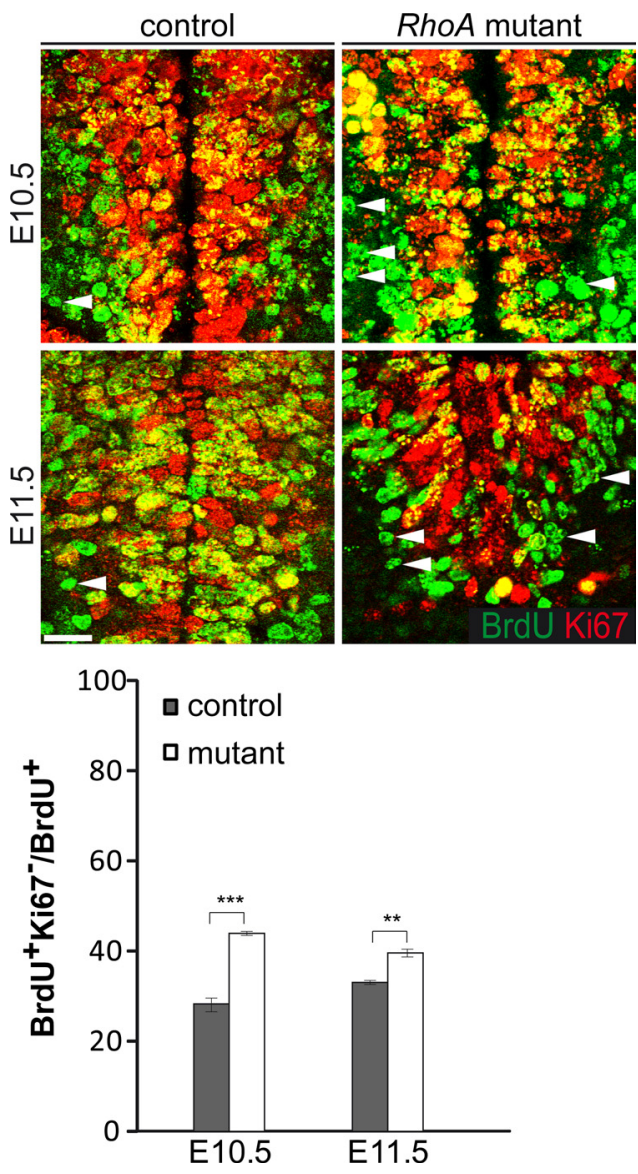

Figure 4. RhoA is required to keep NEPs in the cell cycle. BrdU was given $20 \mathrm{~h}$ before analysis. Arrowheads indicate that cells that have incorporated $\mathrm{BrdU}\left(\mathrm{BrdU}^{+}\right)$but were not proliferative anymore (Ki67 ${ }^{-}$). The fraction of cells being BrdU ${ }^{+} \mathrm{Ki}_{67}^{-}$to all cells being $\mathrm{BrdU}^{+}$was determined. At E10.5, cell-cycle exit is increased from $28.35 \pm 1.34 \%$ in the control to $43.89 \pm 0.35 \%(n=3, p=0.0004)$ and at E11.5 from $32.88 \pm 0.48$ to $39.56 \pm 0.85 \%(n=3, p=0.0023)$. Scale bar, $60 \mu \mathrm{m}$.

bryos $20 \mathrm{~h}$ later. We considered that the BrdU-labeled cells that did not express the proliferation marker Ki67 had divided during the BrdU pulse and exited the cell cycle by the time of the analysis. Our results show that the percentage of cells in the spinal cord exiting the cell cycle was significantly higher in mutants compared with controls at E10.5 and E11.5 (Fig. 4). Next, we determined whether the increase in the percentage of cells exiting the cell cycle corresponded to an increase in the number of cells expressing early differentiation markers. The percentage of cells expressing the neuronal differentiation marker NeuN was increased in the mutant spinal cord at E10.5 and E11.5 compared with controls (Fig. $5 A, C$ ). Similarly, the percentage of cells expressing the stem and undifferentiated progenitor cell marker Sox 2 was decreased in mutants relative to controls (Fig. 4A,D). In addition, the expression of the early neuronal marker Doublecortin was increased in the spinal cords of mutants compared with controls at the same developmental stages (Fig. 4B). We conclude that RhoA is required for maintaining undifferentiated neural progenitors in the cell cycle, contributing indirectly to prevent their differentiation earlier than normal. However, mutant neural stem/progenitor cells are still able to differentiate into distinct neuronal and glial subpopulations as in situ hybridization experiments showed markers Mash1, NeuroD, Math1, Islet-1, and Olig2 to be expressed in the spinal cord of mutant animals (supplemental Figs. 1, 2, available at www.jneurosci.org 
A
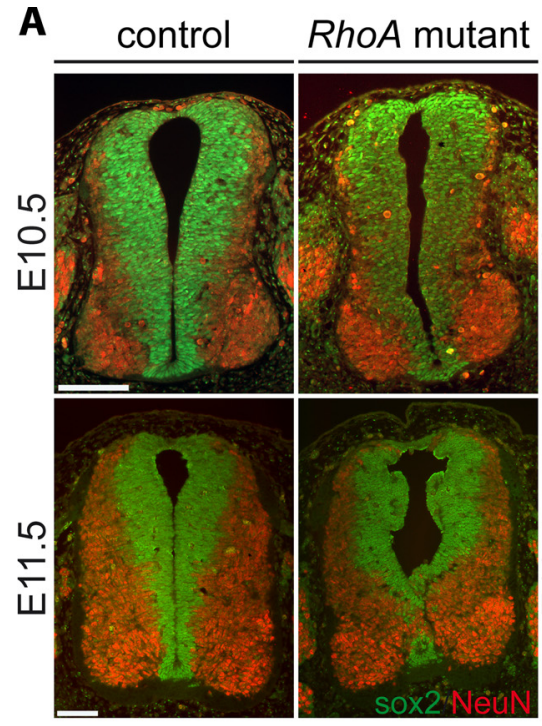

C

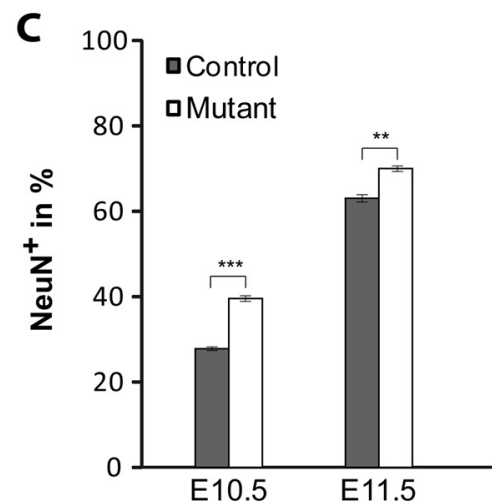

B

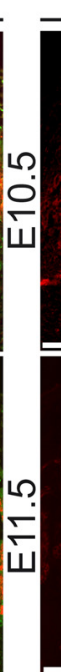

control
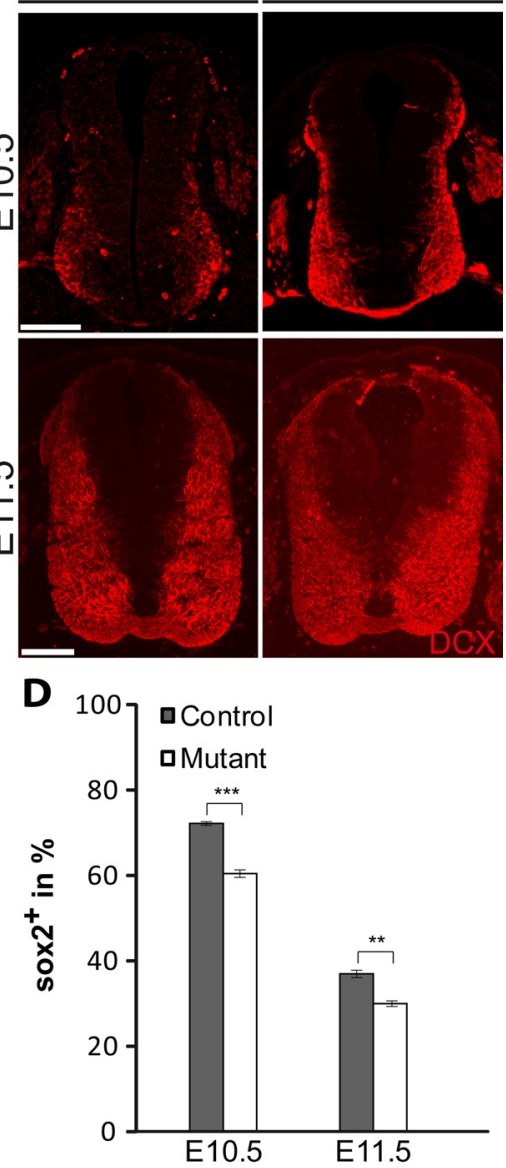

Figure 5. RhoA is required to maintain neural stem/progenitor cells. $\boldsymbol{A}$, Immunohistochemistry for the stem/progenitor marker Sox2 and neuronal marker NeuN. $\boldsymbol{B}$, Immunohistochemistry for Doublecortin (DCX) showed a qualitative increase of early neurons in RhoA mutant spinal cords. C, D, Quantification of staining showed in $\boldsymbol{B}$. The percentage of NeuN-positive cells is increased in the mutants $(\boldsymbol{C})$, and consequently the percentage of Sox2-positive cells is decreased $(\boldsymbol{D})$. The percentage of NeuN-positive cells increases from $27.81 \pm 0.39 \%$ in the control to $39.74 \pm 0.75 \%$ at E10.5 $(n=3, p=0.0001)$ and from $63.11 \pm 0.84$ to $69.87 \pm$ $0.65 \%$ at $\mathrm{E} 11.5$ ( $n=3, p=0.0035$ ). Meanwhile, the Sox2-positive fraction decreases from $72.19 \pm 0.39 \%$ in the control to $60.26 \pm 0.75 \%$ in the mutant at $\mathrm{E} 10.5(n=3, p=0.0001)$ and from $36.92 \pm 0.85 \%$ in the control to $30.14 \pm 0.65 \%$ in the mutant at $\mathrm{E} 11.5(n=3, p=0.0031)$. Scale bars, $100 \mu \mathrm{m}$.

as supplemental material). Furthermore, we analyzed the expression of the Notch target Hes5 by in situ hybridization, the bone morphogenic protein (BMP) target MSX1, Wnt-1, and sonic hedgehog (Shh) and found that their expression domains were not altered in the spinal cords of RhoA mutant embryos (Fig. 6).

\section{RhoA is required for the maintenance of $\mathrm{N}$-cadherin-based cell-cell adhesions}

Alterations in the cell-cell adhesion properties of the ventricular region are known to affect neuroepithelial integrity (Lien et al., 2006a). Because RhoA signaling is necessary for cadherindependent cell-cell contact formation and maintenance in flies and in different mammalian cell types (Sahai and Marshall, 2002; Laplante et al., 2004; Homem and Peifer, 2008) we investigated whether the loss of RhoA affected cell-cell adhesion in the spinal cord neuroepithelium of mutants. We analyzed the distribution of the AJ components $\mathrm{N}$-cadherin, $\beta$-catenin, and actin at the apical side of NEPs lining the lumen of the neural tube by immunofluorescence (Fig. 7). At E10.5, N-cadherin and the apical cellular localizations of $\beta$-catenin and actin were reduced in the RhoA mutants and many cells had lost their normal epithelial

organization, indicating that cell-cell adhesion was already affected (Fig. $7 B-$ $\left.B^{\prime \prime}, F-F^{\prime \prime}, J-J^{\prime \prime}\right)$. These findings were more prominent at E11.5 at which epithelial integrity was dramatically disrupted and large numbers of ventricular cells had started to invade the lumen of the neural tube in areas in where $\mathrm{N}$-cadherin, $\beta$-catenin, and actin were not properly localized (Fig. $\left.7 D-D^{\prime}, H-H^{\prime}, L-L^{\prime}\right)$. In these disrupted regions, NEP polarity, as indicated by the loss of apical Par3 localization, was also disrupted (supplemental Fig. 3C, available at www.jneurosci.org as supplemental material). Such areas had lost epithelial organization and showed formation of rosette-like structures, and the ventral part of the spinal cord lumen was absent (Fig. 2F, $F^{\prime}$ ). This was likely a consequence of the loss of AJs because, at E10.5, Par3 was still localized apically in the VZ of the spinal cord of mutants and was not different from that in controls (supplemental Fig. 3C, available at www. jneurosci.org as supplemental material).

To gain a more detail insight into the affect of RhoA deficiency on localization of AJ components, we generated neurospheres from E13.5 mutant and control embryo spinal cords. N-cadherin was also not properly localized to cell-cell adhesions of cells located at the periphery of neurospheres derived from mutant mice compared with control neurospheres (supplemental Fig. $3 A$, available at www.jneurosci.org as supplemental material). Likely as a consequence, the size and shape of individual neurospheres from RhoA mutants were markedly different from controls (supplemental Figs. $3 A, 4 A$, available at www. jneurosci.org as supplemental material), and the capacity of mutant neurosphere cultures to selfrenew was drastically reduced (supplemental Fig. $4 B$, available at www.jneurosci.org as supplemental material).

We conclude that RhoA is critical for the maintenance of $\mathrm{N}$-cadherin-mediated cell-cell adhesions and, consequently, for the preservation of the integrity of the VZ. Most likely the loss of VZ integrity in the spinal cord of mutants led to the destruction of the stem cell niche and, as a result, to the decline in the numbers of cells expressing the stem and undifferentiated progenitor cell marker Sox2 (Fig. 5A,D).

In contrast to the apical, the basal morphology of NEPs in the mutant spinal cord appeared to be preserved. Laminin immunostaining of the pial surface of both control and mutant spinal cords was continuous and uniform, and nestin immunostaining revealed radial fibers of the neural progenitors contacting the pial surface in RhoA mutants comparable with control embryos (supplementary Fig. 5, available at www.jneurosci.org as supplemental material).

Then we investigated the localization of the RhoA downstream effectors mDial and Rho kinase (ROCK) in the VZ of the spinal cord of E10.5 mutant and control embryos. In epithelial cells in culture, mDial localizes to adherens junctions in a Rho- 
dependent manner (Carramusa et al., 2007). mDial-mediated actin polymerization downstream of Rho is critical for the maintenance of epithelial junctions (Samarin and Nusrat, 2009), and inactivation of mDia1, but not of the RhoA downstream effector ROCK, can disrupt AJs (Sahai and Marshall, 2002; Carramusa et al., 2007). In line with this, apical mDial expression was reduced at the apical surface of mutant $\mathrm{VZ}$ compared with controls (Fig. $8 A$ ). In contrast, ROCK1 (Fig. $8 B$ ) and ROCK2 (data not shown) staining in the same region of the $\mathrm{VZ}$ was comparable between mutant and control embryos.

Next, we analyzed whether expression of $\mathrm{DN}$ mDial in wild-type neural stem/progenitor cells could phenocopy the effect of RhoA ablation and lead to loss of AJs. We expressed DN mDial in neural stem/progenitor cell populations of the VZ of E12.5 mice by in utero electroporation. A GFP expression vector was coelectroporated for following the transfected cells. Because of difficulties on electroporating spinal cord VZ progenitors at E10.5 in utero, we transfected forebrain $\mathrm{VZ}$ progenitors at E12.5 in utero. Expressing DN mDial resulted in the loss of apical N-cadherin immunostaining and of AJs (Fig. 9B, $B^{\prime}$, arrows, $F, F^{\prime \prime}$ ) (supplemental Fig. $6 B$, available at www.jneurosci.org as supplemental material) compared with regions transfected with control GFP vector alone (Fig. $9 A, A^{\prime}, E, E^{\prime \prime}$ ) (supplemental Fig. $6 B$, available at www.jneurosci.org as supplemental material). Furthermore, the expression of DN mDial also lead to loss of apical polarity of VZ neural stem/progenitor cells as shown by disruption of $\mathrm{PKC} \zeta$ localization (Fig. 9D, $D^{\prime}$ ) (supplemental Fig. 6C, transfected region is marked by an arrow, available at www.jneurosci.org as supplemental material) compared with GFP-only (control) expressing cells (Fig. 9C, $C^{\prime}$ ) (supplemental Fig. 6C, available at www.jneurosci.org as supplemental material). Additionally, expression of DN mDial in neural stem/progenitor cells leads to the formation of rosette-like structures (supplemental Fig. $6 B, C$, arrowhead, available at www.jneurosci.org as supplemental material) similar to those formed after the ablation of RhoA (Fig. $2 H^{\prime}$ ). These results suggest that mDial may function downstream of RhoA in the maintenance of AJs in the neuroepithelium.

\section{Discussion}

Our results reveal that RhoA plays a critical role in the development of the mammalian spinal cord. Targeted ablation of RhoA from NEPs in the neuroepithelium of the spinal cord resulted in loss of AJs (Fig. 7) and in related profound structural defects (Fig. 2). In the absence of RhoA, AJ-mediated cell adhesion seems to be severely compromised and NEPs lose their positional information, no longer divide at the apical surface of the neuroepithe- lium, and thus exit the cell cycle and differentiate precociously. As a consequence, the neural stem and progenitor cell pool is significantly reduced in RhoA mutants compared with control embryos. However, the loss of RhoA does not significantly affect the expression of the Notch and BMP downstream effectors, respectively, Hes5 and MSX1, and the expression of the dorsal and ventral signaling factors Wnt-1 and Shh (Fig. 6), or NEP differentiation into neural and glial lineages (supplemental Figs. 1, 2, available at www.jneurosci.org as supplemental material). This is consistent with the well established hypothesis that the formation and maintenance of AJs is essential for the structural organization of different epithelia, including that of the neuroepithelium (Gumbiner, 2005; Lien et al., 2006a). Some of the evidence for which comes from the inactivation of genes involved in AJ formation and maintenance such as N-cadherin (Kadowaki et al., 2007), $\alpha$ E-catenin (Lien et al., 2006b), $\beta$-catenin (Zechner et al., 2003; Junghans et al., 2005), aPKC $\lambda$ (Imai et al., 2006), Lgl (Klezovitch et al., 2004), and Numb (Rasin et al., 2007), which all lead to profound disorganization of the $\mathrm{VZ}$ of the neuroepithelium. 
E 10.5

E 11.5

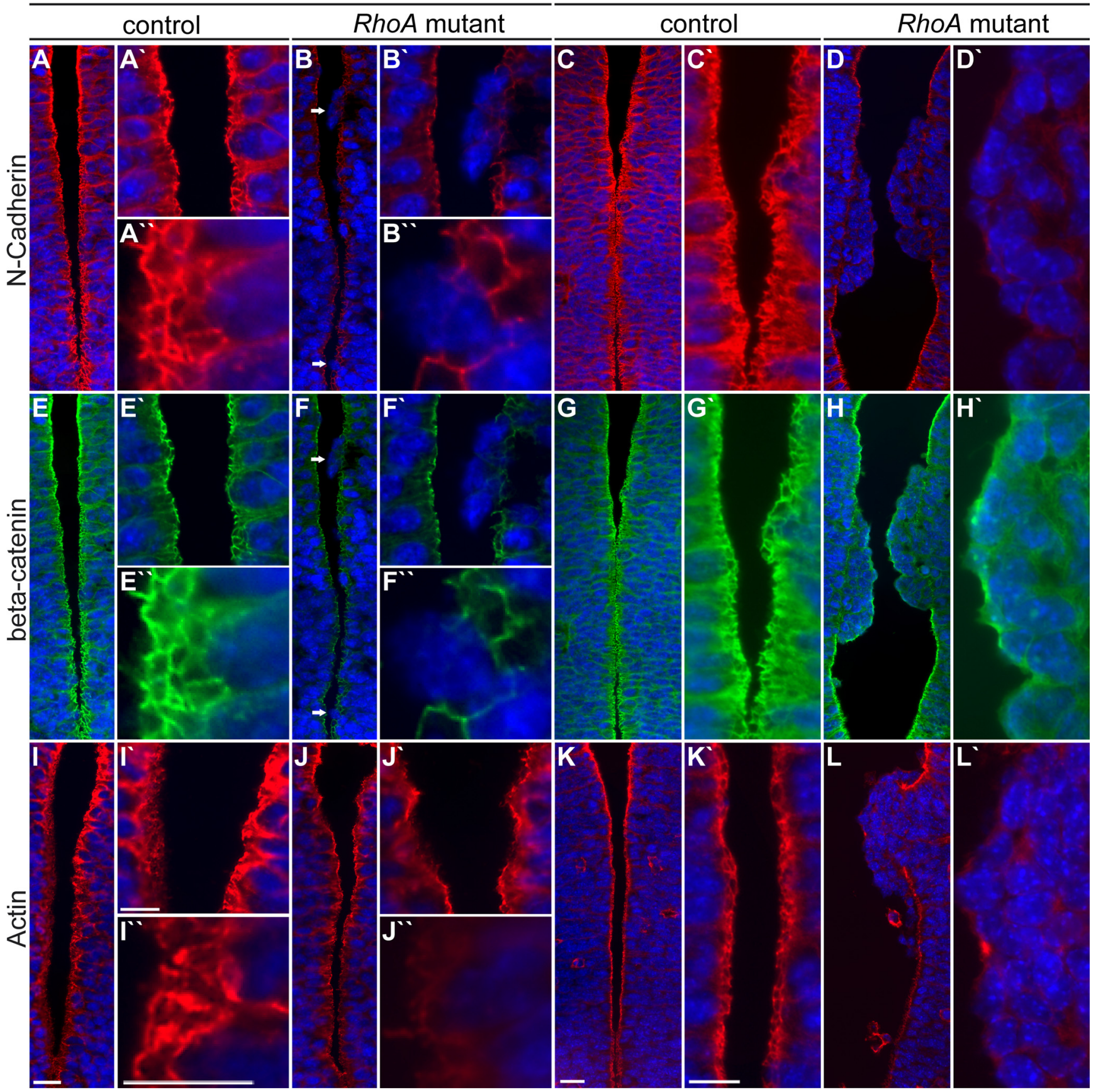

Figure 7. RhoA is required for the maintenance of cell-cell adhesions. $A-L^{\prime}$ Immunohistochemistry to reveal the structure of cell-cell adhesion on control and mutant spinal cord cross-sections. In RhoA mutants, the staining pattern for the cell-cell adhesion markers $\mathrm{N}$-cadherin and $\beta$-catenin is altered at E10.5, and the staining is less intense, less structured, and not continuous at the ventricular surface (arrows in $\boldsymbol{B}, \boldsymbol{F}, \boldsymbol{J}$ and in higher magnification in $\left.\boldsymbol{B}^{\prime}, \boldsymbol{B}^{\prime \prime}, \boldsymbol{F}^{\prime}, \boldsymbol{F}^{\prime \prime}, \boldsymbol{J}^{\prime}, \boldsymbol{J}^{\prime \prime}\right)$. Cortical actin is less intense and appears to be more diffuse and less well structured $\left(\boldsymbol{J}, J^{\prime}, \boldsymbol{J}^{\prime \prime}\right.$ ) in RhoA mutant spinal cords. AtE11.5, the gaps in mutant ventricular surface cell-cell adhesions are more prominent and are identified as the areas in which cells invade the spinal cord lumen $(\boldsymbol{D}, \boldsymbol{H}, \boldsymbol{L}$ and in higher magnification in $\left.D^{\prime}, \boldsymbol{H}^{\prime}, \boldsymbol{L}^{\prime}\right)$. Scale bars: $A-L, 20 \mu \mathrm{m} ; \boldsymbol{A}^{\prime}-\boldsymbol{L}^{\prime}, \boldsymbol{A}^{\prime \prime}-\boldsymbol{J}^{\prime \prime}, 10 \mu \mathrm{m}$.

\section{RhoA is required for $\mathrm{AJ}$ maintenance and for $\mathrm{mDia} 1$} localization to AJs

We show that RhoA is essential for AJ maintenance and cytoskeletal integrity. This is consistent with the findings that the actin cytoskeleton is required for the stabilization and function of mature AJs (Samarin and Nusrat, 2009), and Rho GTPases are major regulators of actin dynamics (Etienne-Manneville and Hall, 2002). Actin dynamics has been implicated in the regulation of AJs in different epithelial cells (Samarin and Nusrat, 2009), including those of the neuroepithelium (Cappello et al., 2006; Chen et al., 2006). We addressed the potential mechanisms by which RhoA could regulate AJ stability. Active RhoA functions through activating downstream effector proteins such as ROCK and mDial (Jaffe and Hall, 2005). Both ROCK and mDial regulate AJs. However, ROCK regulation of acto-myosin contractility seems not to be essential for the maintenance of epithelial junctions. Therefore, we focused on mDia and effects RhoA ablation may have on this arm of the downstream signaling pathway. mDial-mediated actin polymerization downstream of RhoA is essential for localizing cadherins and $\beta$-catenin to cell-cell con- 
tacts, a crucial step in AJ maintenance (Sahai and Marshall, 2002; Carramusa et al., 2007), and in epithelial cell lines, RhoA localizes mDial to AJs (Carramusa et al., 2007). We show that mDial, but not ROCK, localizes to AJs in the neuroepithelium in a RhoA-dependent manner (Fig. 8).

Furthermore, we demonstrate that expression of DN mDial in neural stem/ progenitor cells results in loss of AJs and apical polarity (Fig. 9) (supplemental Fig. 6, available at www.jneurosci.org as supplemental material). Hence, interfering with $\mathrm{mDia}$ function phenocopies the effect of RhoA ablation in neural stem/progenitor cells, suggesting that mDial mediates RhoA function in NEPs. Therefore, we propose that one effect of RhoA ablation from NEPs in the neuroepithelium is to disrupt $\mathrm{mDia}$ association with the AJs, resulting in weakening and disruption of the junctional complex. This is in contrast to a recent report describing the effects of Rhol ablation in mature pupal eye epithelium in Drosophila, suggesting that the role of Drosophila Dia in maintaining AJs is not essential (Warner and Longmore, 2009). Although Dia cooperates with ROCK and myosin to sustain apical cell tension via the regulation of filamentous actin, AJ maintenance depends only on Rhol inhibition of DE-cadherin endocytosis in Drosophila, possibly by blocking Cdc42/Par6 activity (Warner and Longmore, 2009). This appears not to be the case in the mammalian nervous system (see below) and is also in contrast to previous analyses in Drosophila epithelia (Homem and Peifer, 2008).

Cdc42 also regulates AJ maintenance in the mammalian neuroepithelium (Cappello et al., 2006; Chen et al., 2006). Conditional ablation of Cdc42, like RhoA, leads to loss of apical polarity and AJs (Cappello et al., 2006; Chen et al., 2006). Therefore, we addressed whether loss of RhoA has an effect on other members of the Rho GTPase family, potentially reducing their expression and activity. We show that, whereas the loss of RhoA does not affect the levels or activity of Racl and does not result in a loss of $\mathrm{Cdc} 42$, there is a significant decrease in Cdc42 activation levels in neurosphere cultures derived from RhoA mutant spinal cords (supplemental Fig. 3C, available at www.jneurosci.org as supplemental material). It remains unclear whether this is an indirect result of loss of AJs in the RhoA mutants or could have a causative effect on the stability of AJs.

\section{Loss of RhoA results in the formation of dysplasias}

In areas in which RhoA was deleted in the neuroepithelium and in which AJs were absent, the loss of normal VZ organization was associated with the formation of dysplasias from E11.5 onward (Fig. $2 D^{\prime}, F^{\prime}, H^{\prime}, J^{\prime}$ ), resembling the process of epithelial-mesenchymal transition (EMT). EMT is a complex process occurring during normal development and in different pathologies, most notably during the formation of metastases (Thiery, 2002; Lee et al., 2006). EMT involves disruption of epithelial cell-cell junctions, loss of apico-basal polarity, breakdown of cell-basal membrane interactions, and changes in cytoarchitecture (Hay, 1995). The process can be initiated by dysregulation of cadherin and catenin signaling (Hay, 1995; Thiery, 2002) and, most relevant in the context our results, by downregulation of RhoA signaling (Nakaya et al., 2008). After E11.5, NEPs in the spinal cords of RhoA mutants contained rosette-like structures, closely resembling those seen in some primary neuroepithelial tumors. Because Rho GTPase signaling has been linked to different types of cancer (Sahai and Marshall, 2002) and tumorigenesis (Karlsson et al., 2009), our observations have potential implications for brain tumor formation. Indeed, these rosettes were also reminiscent of those observed by disruption of the AJ in the neuroepithelium by function-blocking antibodies directed against the ectodomain of N-cadherin (Gänzler-Odenthal and Redies, 1998 ) and are also observed when interfering with mDial function (supplemental Fig. 6, available at www.jneurosci.org as supplemental material). This lends support for our hypothesis that a key function for RhoA in the developing nervous system is to maintain cell adhesion and polarity by dynamic regulation of AJs and cell-cell contacts, possibly through its downstream effector mDia1.

\section{RhoA is required for NEP maintenance}

Our results indicate that cell proliferation and survival is significantly reduced in the neuroepithelium of RhoA mutants, and mutant cells withdrew from the cell cycle and differentiated precociously (Figs. 4, 5). Mitotic cells were frequently found in nonapical positions (Fig. 3), but it cannot be ruled out that some of these cells are not NEPs dividing in abnormal positions but represent abnormally behaving progenitors that have re-entered the cell cycle.

Instructive cues originating at the neural tube lumen are thought to regulate proliferation and survival of NEPs through receptors located on their apical membrane (Götz and Huttner, 2005). It is likely that, during loss of AJs, RhoA mutant NEPs, which were not properly anchored to the apical surface of the neuroepithelium, lose their positional information and consequently their ability to integrate proliferative and survival signals 

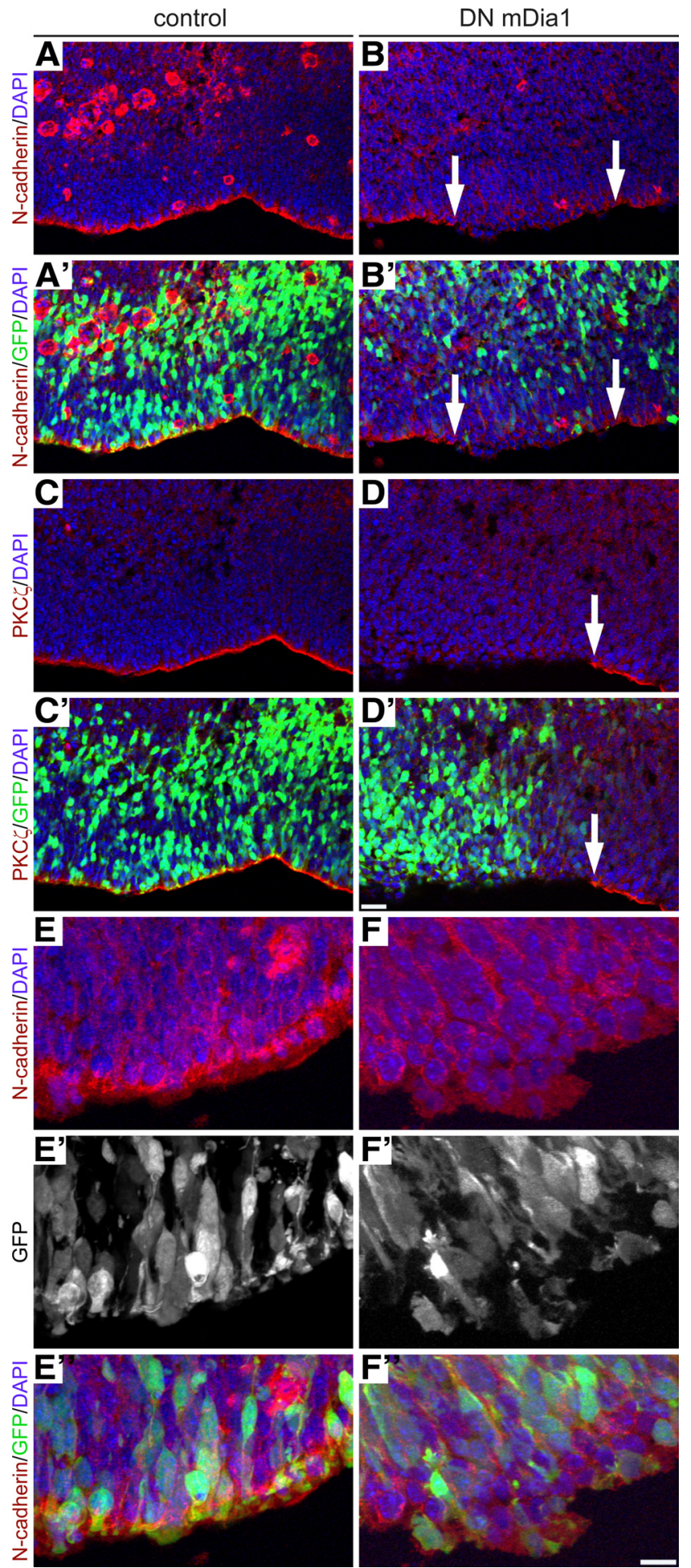

Figure 9. Overexpression of DN mDia 1 in neural stem progenitor cells results in the loss of AJs and apical polarity. Forebrain progenitors of wild-type E12.5 embryos were electroporated in utero with a GFP expression vector (control) or coelectroporated with the GFP vector and DN mDia 1 expression vector and analyzed $24 \mathrm{~h}$ later. Transfected cells were identified by GFP expression. $\boldsymbol{A}-\boldsymbol{F}^{\prime \prime}$, Confocal images of immunohistochemistry for $\mathrm{N}$-cadherin $\left(\boldsymbol{A}, \boldsymbol{A}^{\prime}, \boldsymbol{B}, \boldsymbol{B}^{\prime}\right.$ and $\mathrm{z}$-projections of higher magnification in $\left.\boldsymbol{E}, \boldsymbol{E}^{\prime \prime}, \boldsymbol{F}, \boldsymbol{F}^{\prime \prime}\right)$ show a loss of AJs at the ventricular surface in neural stem/progenitor cells transfected with DN mDia1 (areas of lost AJs marked by arrows in $\boldsymbol{B}, \boldsymbol{B}^{\prime}$, and $\boldsymbol{F}, \boldsymbol{F}^{\prime \prime}$ ) but not in cells expressing GFP only $\left(\boldsymbol{A}, \boldsymbol{A}^{\prime}\right.$ and $\left.\boldsymbol{E}, \boldsymbol{E}^{\prime \prime}\right)$. Apical polarity and disruption of PKC $\zeta$ localization is lost after DN mDia1 expression (marked by an arrow in $\boldsymbol{D}, \boldsymbol{D}^{\prime}$ ) compared with GFP-expressing control areas $\left(\boldsymbol{C}, \boldsymbol{C}^{\prime}\right)$. Scale bars: $\boldsymbol{A}-\boldsymbol{D}^{\prime}, 50 \mu \mathrm{m} ; \boldsymbol{E}-\boldsymbol{F}^{\prime \prime}, 20 \mu \mathrm{m}$. at their apical membranes. AJs are thought to provide epithelial cells with information about their position, cell-type specificity, and overall density of their neighbors (Lien et al., 2006a). In NEPs, loss of apical $\beta$-catenin, part of the cadherin-catenin complex forming the AJs, results in proliferation defects leading to the reduction of the neural stem cell pool (Machon et al., 2003; Zechner et al., 2003). RhoA activity has also been implicated in the direct regulation of cell cycle progression in a cell-autonomous way in a variety of different cell types (Jaffe and Hall, 2005; Narumiya and Yasuda, 2006). RhoA promotes G1-to-S-phase progression by increasing the amounts of cyclin D1 and reducing the levels of the cell-cycle inhibitors p21cip1 and p27kip1 (Karlsson et al., 2009). Furthermore, RhoA regulates the ratio of symmetric versus asymmetric cell divisions in the chick neuroepithelium by controlling spindle orientation favoring asymmetric neurogenic cell divisions (Roszko et al., 2006). These mechanisms may explain the decrease in NEP proliferation and the increase in cell-cycle exit and differentiation observed in RhoA-mutant neuroepithelium compared with controls embryos (Figs. 3-5).

In summary, using tissue-specific conditional gene ablation, we show a key role for RhoA signaling in the control of mammalian CNS development. Although the requirements to regulate stem cell self-renewal, proliferation, and fate acquisition are likely to be cell-type and context specific, our data draw additional attention to the growing importance of Rho GTPase signaling in cellular and developmental neurobiology (Cappello et al., 2006; Chen et al., 2006; Feltri et al., 2008; Fuchs et al., 2009; Leone et al., 2010). Our findings also indicate that a better understanding of such signaling pathways will increase our knowledge of the mechanisms regulating nervous system function in health and disease.

\section{References}

Aaku-Saraste E, Hellwig A, Huttner WB (1996) Loss of occludin and functional tight junctions, but not ZO-1, during neural tube closure-remodeling of the neuroepithelium prior to neurogenesis. Dev Biol 180:664-679.

Benninger Y, Thurnherr T, Pereira JA, Krause S, Wu X, Chrostek-Grashoff A, Herzog D, Nave KA, Franklin RJ, Meijer D, Brakebusch C, Suter U, Relvas JB (2007) Essential and distinct roles for cdc42 and racl in the regulation of Schwann cell biology during peripheral nervous system development. J Cell Biol 177:1051-1061.

Cappello S, Attardo A, Wu X, Iwasato T, Itohara S, Wilsch-Bräuninger M, Eilken HM, Rieger MA, Schroeder TT, Huttner WB, Brakebusch C, Götz M (2006) The Rho-GTPase cdc42 regulates neural progenitor fate at the apical surface. Nat Neurosci 9:1099-1107.

Carramusa L, Ballestrem C, Zilberman Y, Bershadsky AD (2007) Mammalian diaphanous-related formin Dial controls the organization of E-cadherin-mediated cell-cell junctions. J Cell Sci 120:3870-3882.

Chen L, Liao G, Yang L, Campbell K, Nakafuku M, Kuan CY, Zheng Y (2006) Cdc42 deficiency causes Sonic hedgehog-independent holoprosencephaly. Proc Natl Acad Sci U S A 103:16520-16525.

Chen L, Liao G, Waclaw RR, Burns KA, Linquist D, Campbell K, Zheng Y, Kuan CY (2007) Racl controls the formation of midline commissures and the competency of tangential migration in ventral telencephalic neurons. J Neurosci 27:3884-3893

Chen L, Melendez J, Campbell K, Kuan CY, Zheng Y (2009) Rac1 deficiency in the forebrain results in neural progenitor reduction and microcephaly. Dev Biol 325:162-170.

De Pietri Tonelli D, Calegari F, Fei JF, Nomura T, Osumi N, Heisenberg CP, Huttner WB (2006) Single-cell detection of microRNAs in developing vertebrate embryos after acute administration of a dual-fluorescence reporter/sensor plasmid. Biotechniques 41:727-732.

Etienne-Manneville S, Hall A (2002) Rho GTPases in cell biology. Nature 420:629-635.

Feltri ML, Suter U, Relvas JB (2008) The function of RhoGTPases in axon ensheathment and myelination. Glia 56:1508-1517.

Fuchs S, Herzog D, Sumara G, Büchmann-Møller S, Civenni G, Wu X, Chrostek-Grashoff A, Suter U, Ricci R, Relvas JB, Brakebusch C, Sommer 
L (2009) Stage-specific control of neural crest stem cell proliferation by the small rho GTPases Cdc42 and Rac1. Cell Stem Cell 4:236-247.

Gänzler-Odenthal SI, Redies C (1998) Blocking N-cadherin function disrupts the epithelial structure of differentiating neural tissue in the embryonic chicken brain. J Neurosci 18:5415-5425.

Götz M, Huttner WB (2005) The cell biology of neurogenesis. Nat Rev Mol Cell Biol 6:777-788.

Gumbiner BM (2005) Regulation of cadherin-mediated adhesion in morphogenesis. Nat Rev Mol Cell Biol 6:622-634.

Hall A (1998) Rho GTPases and the actin cytoskeleton. Science 279:509514.

Hay ED (1995) An overview of epithelio-mesenchymal transformation. Acta Anat (Basel) 154:8-20.

Homem CC, Peifer M (2008) Diaphanous regulates myosin and adherens junctions to control cell contractility and protrusive behavior during morphogenesis. Development 135:1005-1018.

Imai F, Hirai S, Akimoto K, Koyama H, Miyata T, Ogawa M, Noguchi S, Sasaoka T, Noda T, Ohno S (2006) Inactivation of aPKClambda results in the loss of adherens junctions in neuroepithelial cells without affecting neurogenesis in mouse neocortex. Development 133:1735-1744.

Jaffe AB, Hall A (2005) Rho GTPases: biochemistry and biology. Annu Rev Cell Dev Biol 21:247-269.

Junghans D, Hack I, Frotscher M, Taylor V, Kemler R (2005) Beta-cateninmediated cell-adhesion is vital for embryonic forebrain development. Dev Dyn 233:528-539.

Kadowaki M, Nakamura S, Machon O, Krauss S, Radice GL, Takeichi M (2007) N-cadherin mediates cortical organization in the mouse brain. Dev Biol 304:22-33.

Karlsson R, Pedersen ED, Wang Z, Brakebusch C (2009) Rho GTPase function in tumorigenesis. Biochim Biophys Acta 1796:91-98.

Klezovitch O, Fernandez TE, Tapscott SJ, Vasioukhin V (2004) Loss of cell polarity causes severe brain dysplasia in Lgll knockout mice. Genes Dev 18:559-571.

Kosodo Y, Röper K, Haubensak W, Marzesco AM, Corbeil D, Huttner WB (2004) Asymmetric distribution of the apical plasma membrane during neurogenic divisions of mammalian neuroepithelial cells. EMBO J 23:2314-2324.

Kriegstein A, Alvarez-Buylla A (2009) The glial nature of embryonic and adult neural stem cells. Annu Rev Neurosci 32:149-184.

Laplante I, Béliveau R, Paquin J (2004) RhoA/ROCK and Cdc42 regulate cell-cell contact and $\mathrm{N}$-cadherin protein level during neurodetermination of P19 embryonal stem cells. J Neurobiol 60:289-307.

Lee JM, Dedhar S, Kalluri R, Thompson EW (2006) The epithelialmesenchymal transition: new insights in signaling, development, and disease. J Cell Biol 172:973-981.

Leone DP, Srinivasan K, Brakebusch C, McConnell SK (2010) The rho GTPase Racl is required for proliferation and survival of progenitors in the developing forebrain. Dev Neurobiol 70:659-678.

Lien WH, Klezovitch O, Vasioukhin V (2006a) Cadherin-catenin proteins in vertebrate development. Curr Opin Cell Biol 18:499-506.
Lien WH, Klezovitch O, Fernandez TE, Delrow J, Vasioukhin V (2006b) alphaE-catenin controls cerebral cortical size by regulating the hedgehog signaling pathway. Science 311:1609-1612.

Machon O, van den Bout CJ, Backman M, Kemler R, Krauss S (2003) Role of beta-catenin in the developing cortical and hippocampal neuroepithelium. Neuroscience 122:129-143.

Marthiens V, ffrench-Constant C (2009) Adherens junction domains are split by asymmetric division of embryonic neural stem cells. EMBO Rep 10:515-520.

Nakaya Y, Sukowati EW, Wu Y, Sheng G (2008) RhoA and microtubule dynamics control cell-basement membrane interaction in EMT during gastrulation. Nat Cell Biol 10:765-775.

Narumiya S, Yasuda S (2006) Rho GTPases in animal cell mitosis. Curr Opin Cell Biol 18:199-205.

Niwa H, Yamamura K, Miyazaki J (1991) Efficient selection for highexpression transfectants with a novel eukaryotic vector. Gene 108: 193-199.

Paratore C, Suter U, Sommer L (1999) Embryonic gene expression resolved at the cellular level by fluorescence in situ hybridization. Histochem Cell Biol 111:435-443.

Rasin MR, Gazula VR, Breunig JJ, Kwan KY, Johnson MB, Liu-Chen S, Li HS, Jan LY, Jan YN, Rakic P, Sestan N (2007) Numb and Numbl are required for maintenance of cadherin-based adhesion and polarity of neural progenitors. Nat Neurosci 10:819-827.

Roszko I, Afonso C, Henrique D, Mathis L (2006) Key role played by RhoA in the balance between planar and apico-basal cell divisions in the chick neuroepithelium. Dev Biol 298:212-224.

Sahai E, Marshall CJ (2002) RHO-GTPases and cancer. Nat Rev Cancer 2:133-142.

Samarin S, Nusrat A (2009) Regulation of epithelial apical junctional complex by Rho family GTPases. Front Biosci 14:1129-1142.

Sander EE, van Delft S, ten Klooster JP, Reid T, van der Kammen RA, Michiels F, Collard JG (1998) Matrix-dependent Tiam1/Rac signaling in epithelial cells promotes either cell-cell adhesion or cell migration and is regulated by phosphatidylinositol 3-kinase. J Cell Biol 143:1385-1398.

Soriano P (1999) Generalized lacZ expression with the ROSA26 Cre reporter strain. Nat Genet 21:70-71.

Thiery JP (2002) Epithelial-mesenchymal transitions in tumour progression. Nat Rev Cancer 2:442-454.

Thurnherr T, Benninger Y, Wu X, Chrostek A, Krause SM, Nave KA, Franklin RJ, Brakebusch C, Suter U, Relvas JB (2006) Cdc42 and Rac1 signaling are both required for and act synergistically in the correct formation of myelin sheaths in the CNS. J Neurosci 26:10110-10119.

Warner SJ, Longmore GD (2009) Distinct functions for Rho1 in maintaining adherens junctions and apical tension in remodeling epithelia. J Cell Biol 185:1111-1125.

Zechner D, Fujita Y, Hülsken J, Müller T, Walther I, Taketo MM, Crenshaw EB 3rd, Birchmeier W, Birchmeier C (2003) beta-Catenin signals regulate cell growth and the balance between progenitor cell expansion and differentiation in the nervous system. Dev Biol 258:406-418. 